Ensino, Saúde e Ambiente - V6 (3), pp. 218-227, dez. 2013

\title{
EDUCAÇÃO CIENTÍFICA NOS ANOS INICIAIS: NOVAS INTERFACES ENTRE A PSICOLOGIA DO DESENVOLVIMENTO E O ENSINO DE CIÊNCIAS ${ }^{1}$
}

\section{SCIENCE EDUCATION IN THE EARLY YEARS: NEW INTERFACES BETWEEN THE PSYCHOLOGY OF DEVELOPMENT AND EDUCATION OF SCIENCES ${ }^{1}$}

\author{
Luiza Oliveira $^{1}$; Rose Latini ${ }^{1}$ \\ Carlos Vitor de Alencar Carvalho ${ }^{2}$; Anderson Rocha da Silva ${ }^{3}$; \\ Eloisa Porto Corrêa ${ }^{4}$; Ana Leal Almeida ${ }^{4}$; Hermes Ferreira ${ }^{4}$; Marinea Rodrigues ${ }^{4}$; \\ Ana Flávia Marins ${ }^{5}$; Esandra Magalhães ${ }^{5}$; Greicy Alcântara ${ }^{5}$ \\ 1 Professora do Curso de Psicologia e Professora Colaboradora do Programa Stricto Sensu em Ensino de \\ Ciências da Natureza da Universidade Federal Fluminense \\ 2 Professor Permanente do Programa em Ensino de Matemática da Universidade Severino Sombra \\ 3 Professor do Instituto Federal de Educação, Ciência e Tecnologia do Rio de Janeiro \\ 4 Professores do Núcleo de Pesquisa e Extensão da Universidade Severino Sombra \\ 5 Alunas de Iniciação Científica da Universidade Severino Sombra
}

\begin{abstract}
RESUMO
As pesquisas acerca do ensino de ciências nos primeiros anos escolares são recentes, haja vista esta etapa da formação ser ainda identificada com um único objetivo - o aprendizado da leitura e da escrita da língua portuguesa. Este fato pode ser explicado, sobretudo, pela constituição das abordagens acerca da aprendizagem científica, que, tradicionalmente, foi vinculada exclusivamente a um momento específico do desenvolvimento psicológico - constituição da capacidade de realizar as operações lógico formais. $\mathrm{O}$ artigo apresentado tem por finalidade apresentar e discutir a aprendizagem científica como possibilidade para os anos iniciais, a partir de uma abordagem que valoriza a perspectiva de que aprender ciências significa apropriar-se de um dos códigos sociais que são fundamentais para a possibilidade de exploração e compreensão do meio social e natural, condição fundamental para que a aprendizagem científica se dê em outros estágios da vida. Para tanto, é necessário desenvolver novas interfaces entre a Psicologia do Desenvolvimento e a área de Ensino de Ciências.
\end{abstract}

Palavras-chave: Anos Iniciais; Ensino Fundamental; Ensino de Ciências; Formação de Professores.

\footnotetext{
ABSTRACT

The research on the teaching of science in the early grades are recent, given this stage of formation is still identified with a single goal - the development of reading and writing the English language. This fact can be explained mainly by the constitution approaches to the scientific learning, which traditionally has been linked exclusively to

$1 \quad$ Este artigo é resultado inicial das pesquisas realizadas a partir de um projeto fomentado pela FAPERJ, cujo objetivo final foi o desenvolvimento e a implantação de um Laboratório de Ciências e Artes para os Anos Iniciais em uma Escola do Ensino Fundamental.

1 This article presents the research initial results conducted from a project promoted by FAPERJ. The final objective was the development and implementation of a Laboratory Sciences and Arts for the first years in a school of elementary school.
} 
a specific moment of psychological development - Formation of ability to make logical and formal operations. This article aims to present and discuss scientific learning as a possibility for the early years, from an approach that values the idea that learning science means to take ownership of one of the social codes that are fundamental to the possibility of exploring and understanding the social and natural environment, fundamental condition for scientific learning be given in other stages of life. Therefore, it's necessary to develop new interfaces between developmental psychology and the area of Science Education.

Keywords: Early Years, Primary Education, Science Education, Teacher Formation.

\section{INTRODUÇÃO}

Este artigo, de abordagem teórica, propõe uma análise sobre a importância do ensino de ciências nos anos iniciais da vida escolar. Para tanto, é preciso ir além da suposição de que é necessária apenas a inserção legal da educação científica na educação formal dos primeiros anos. Pois, a Lei de Diretrizes e Bases da Educação Nacional de 1971, Lei 5692/71, tornou obrigatório no Brasil o ensino de ciências nos anos iniciais (quatro primeiros anos) do antigo Primeiro Grau, porém, este não foi fator de valorização da aprendizagem científica nesta etapa da vida escolar.

Além dos fatos referentes às dificuldades da aprendizagem científica em qualquer período da vida escolar, muito estudadas pela pesquisa na área de ensino de ciências, pode-se fazer um recorte acerca de uma condição, relativa à educação em ciências, que foi produzida pelos vários modelos pelos quais a área foi sendo constituída. Tais modelos, tradicionalmente, vincularam a aprendizagem científica ao objetivo de formar cientistas, seja por meio da abordagem empírica, seja com base na abordagem desenvolvimentista piagetiana, passando pelas ideias de Posner. Além disso, afirmaram um momento ideal do desenvolvimento cognitivo para a aprendizagem científica, a etapa lógico formal da construção do pensamento. Estes fatos favoreceram os estudos e as pesquisas da área de Ensino de Ciências concentrados apenas em uma etapa da vida escolar - o ensino secundário. Este artigo, porém, discute, não pelo viés da formação de professores e nem pela perspectiva do uso de metodologias, a educação científica nos anos iniciais da escolarização, ou seja, o texto analisa o porquê de se ensinar ciências nesse momento da aprendizagem sistematizada, a partir da explicação acerca do desenvolvimento da formação de conceitos, tendo como aporte teórico a teoria de Vygotsky. 
A educação científica foi inicialmente embasada por uma concepção empirista, que valorizava o treinamento e a memorização (KRASILCHIK, 2000). Passou, ainda, pelo Modelo da Mudança Conceitual (MMC) de Posner, que enfatizava a necessidade do estabelecimento da insatisfação com as concepções existentes (ARRUDA e VILLANI, 1994). Tais modelos foram amplamente criticados, pois o primeiro tomava o aluno como mero objeto do processo ensino-aprendizagem e o MMC não constituía explicação acerca de como se dá o desenvolvimento cognitivo.

Estas críticas expuseram que para as pesquisas na área de Ensino de Ciências não bastava produzir metodologias para o ensino de ciências a partir das abordagens citadas, mas era preciso entender o processo da aprendizagem científica. No Brasil dos anos de 1980, a teoria de J. Piaget cumpriu esta finalidade, pois propôs um processo de aprendizagem que não era resultado de práticas de memorização e condicionamento, mas que se dava pelo desenvolvimento das estruturas cognitivas dos sujeitos. Concepção inovadora na Educação, porém fundamentada no conceito de sujeito abstrato, a-histórico e, portanto, desconectado do contexto histórico-social. Além disso, a abordagem piagetiana traz uma concepção desenvolvimentista e determinista, ou seja, explica a construção do conhecimento de maneira linear, a partir das estruturas psicológicas, em que a formação de conceitos é construída de uma forma mais rudimentar para uma mais elaborada, denominada lógico formal, sem possibilidade de retrocesso e em que a forma determina o conteúdo. Isto significa que se foi desenvolvida a capacidade de entender o mundo pelo pensamento abstrato, não há retrocesso, independentemente do conteúdo e do contexto.

Assim, a teoria piagetiana, lida e aplicada a partir de seus aspectos reducionistas, institui a aprendizagem científica a partir de uma perspectiva linear e ascendente, que se contrapõe ao desenvolvimento dos conceitos espontâneos. Esta abordagem, dominante nas pesquisas em Ensino de Ciências nas décadas de 1980 e de 1990, não favorece a aprendizagem científica nos primeiros anos da vida escolar, pois expressa que o pensamento desses anos precisa ser modificado para que conceitos mais elaborados, tais como os científicos, possam ser desenvolvidos, o que se daria apenas nos anos da adolescência, do desenvolvimento do pensamento lógico formal. Consequentemente, a maior parte das pesquisas em Ensino de Ciências objetiva o Ensino Médio, momento em que o pensamento lógico formal está se constituindo, ficando o ensino de ciências dos anos anteriores apenas como uma passagem ao ensino secundário. 
Entretanto, analisando a abordagem da Psicologia do Desenvolvimento para além da teoria piagetiana, é possível estabelecer novo tipo de vínculo entre o conhecimento espontâneo e o conhecimento científico. O recorte teórico a que recorremos, encontra-se instituído na obra de Vygotsky (2001), que engendra uma nova Psicologia ao produzir um lugar para o sujeito do conhecimento, ressaltando a importância da interação social no processo de construção do conhecimento. (VYGOTSKY, 2001).

Desde os primeiros dias do desenvolvimento da criança, suas atividades adquirem um significado próprio num sistema de comportamento social e, sendo dirigidas a objetos definidos, são refratadas a partir do prisma do ambiente da criança. $\mathrm{O}$ caminho do objeto da criança e desta até o objeto passa através de outra pessoa. Essa estrutura humana complexa é o produto de um processo de desenvolvimento profundamente enraizado nas ligações entre história individual e história social (VYGOTSKY, 1984, p. 33).

Além disto, segundo Vygotsky, aprende-se antes mesmo de entrar no sistema formal de ensino, ou seja, os conceitos espontâneos são aprendidos na relação com o outro da cultura. Na Escola, porém, é preciso lidar com os conceitos sistematizados, os conceitos científicos, pois

\begin{abstract}
quando se transmite à criança um conceito sistemático, ensinam-se coisas que ela não pode ver ou vivenciar diretamente: a relação com um objeto é mediada por um conceito científico (...) os dois processos - dos conceitos espontâneos e dos conceitos científicos - se relacionam e se influenciam constantemente, fazendo parte de um único processo: o desenvolvimento da formação de conceitos (FREITAS, 1995, p. 102).
\end{abstract}

Portanto, a perspectiva vigotskiana apresenta possibilidade de nova interface entre a Área de Ensino de Ciências e a Psicologia do Desenvolvimento. Vygotsky apresenta, por meio do conceito de sujeito histórico-social, uma nova concepção de desenvolvimento cognitivo, que, diferente dos modelos da Psicologia tradicional, baseada nos ideais do sujeito cartesiano, prevê a constituição histórico-social do sujeito, inaugurando outro objeto de estudo para a Psicologia, ao enfatizar os vínculos entre pensamento e linguagem, a mediação da cultura no processo de subjetivação e, consequentemente, o processo de internalização de conhecimentos elaborados a partir da cultura.

Assim, para Vygotsky, além de não ser possível subordinar a aprendizagem aos efeitos dos estímulos ambientais e às técnicas de condicionamento, numa crítica direta ao empirismo, também não é possível remeter a aprendizagem ao desenvolvimento 
individual fruto das estruturas psicológicas, numa clara discordância com a teoria piagetiana (FREITAS, 1995). É nesta perspectiva teórica que analisaremos o tema deste artigo.

\section{O ENSINO DE CIÊNCIAS NAS SÉRIES INICIAIS}

A partir do final da década de 1980, o objetivo do ensino de ciências modificouse do ideal de formar cientistas, seja com ênfase empirista ou ênfase piagetiana, e foi se aproximando da finalidade de formar para a vida. Isto é, a aprendizagem científica começou a ser entendida como a possibilidade de apropriação de uma linguagem - os códigos da Ciência, que nos permite entender o mundo no qual estamos inseridos. (DELIZOICOV E ANGOTI, 1990; DELIZOICOV; ANGOTI E PERNAMBUCO, 2002). “A educação em Ciência deve dar prioridade à formação de cidadãos [...] capazes de participar ativa e responsavelmente em sociedades que se querem abertas e democráticas. Prioridade não exclusividade" (CHASSOT apud CACHAPUZ, PRAIA e JORGE, 2004, pp. 366-7).

Desde meados, oficialmente, a educação brasileira vai afirmando este novo lugar para o ensino de ciências nas escolas, tal como exposto nos Parâmetros Curriculares Nacionais para o Ensino Fundamental (BRASIL, 1997), com a seguinte definição de Ciência: "um conhecimento que colabora para a compreensão do mundo e suas transformações, para reconhecer o homem como parte do universo e como indivíduo (...), favorecendo o desenvolvimento da postura reflexiva, crítica, questionadora e investigativa" (BRASIL, 1997, pp. 24-5)

Esta forma de entender as relações entre a Ciência e a Escola é inovadora e necessita romper com os modelos empiristas (objetivistas) e racionalistas (subjetivistas), tanto na área de Ensino de Ciências como na Psicologia do Desenvolvimento, pois o entendimento contemporâneo acerca das funções da Ciência precisa de um novo conceito de sujeito, para além da dicotomia constituída pelo modelo da Modernidade. A perspectiva é de um sujeito que é parte do ambiente, sendo por ele produzido, mas que, ao mesmo tempo, é capaz de ação reflexiva e transformadora desse contexto. Este conceito de sujeito tem aporte teórico, que é nomeado pelas teses marxistas. E no campo da Psicologia do Desenvolvimento, um aporte importante é L. Vygotsky.

É possível entender a crítica que Vygotsky (2001) faz às abordagens empiristas e subjetivistas por meio da análise de seus estudos sobre linguagem, preocupação central 
da obra do autor, já que a entende como constituidora do sujeito. Para Vygotsky, a linguagem não é invariável ao longo do desenvolvimento, mas determinante. $\mathrm{O}$ autor explica esta máxima da sua teoria a partir do conceito de significado da palavra, que para ele tem dois componentes: o significado propriamente dito, que se refere à convenção arbitrária estabelecida entre o significante e o significado que compõem um signo, e o sentido é aquilo que indica o significado da palavra para cada indivíduo, sentido marcado pelo contexto e pela vivência de cada um. Ao analisar o vínculo entre linguagem e pensamento, o autor inova, pois expressa que a fala não é mera expressão do pensamento e o pensamento não é simplesmente expresso em palavras. É por meio da fala que o pensamento existe, se constitui. Estes aspectos definem a forma de entender o conceito de desenvolvimento para Vygotsky (1984).

O desenvolvimento, para Vygotsky, é prospectivo, pois como a formação do sujeito se dá por meio da internalização (fala interior) de processos interpsicológicos (fala exterior), são os mecanismos de aprendizado que movimentam o desenvolvimento. Este processo acontece de fora para dentro, sendo fundamental a atuação de outros sujeitos. É assim que o homem se constitui como sujeito: há uma intervenção de membros socialmente mais maduros, que significam para as crianças como ser sujeito numa determinada cultura.

A cooperação do outro da cultura pode ser sistematizada, tal como acontece nos espaços formais de ensino. A aprendizagem desenvolvida nos espaços escolares tem, portanto, muita importância na teoria de Vygotsky.

Esta concepção de sujeito e, cosequentemente de aprendizagem, revela nova forma de pensar os vínculos entre o conhecimento espontâneo e o conhecimento científico, pois traz a ideia de que desenvolvimento e aprendizagem não são fenômenos dissassociados, pois a criança desde seu nascimento vive uma série de experiências no cotidiano, o que significa aprendizagem também, que se refere a conceitos espontâneos. $\mathrm{O}$ conceito científico se refere aos eventos não acessíveis diretamente à criança, na escola, por exemplo, um conceito simples constituído nas relações do dia a dia se torna mais complexo. Por exemplo, como cita Rego (2000), no dia a dia, a criança constrói o conceito de gato e o diferencia de outra categoria: carro, por exemplo. Com a aprendizagem escolar, o conceito "gato" será incluído num sistema conceitual de abstrações graduais que partem do objeto concreto e vão alcançando cada vez mais complexidade: gato, mamífero, vertebrado, ser vivo. No desenvolvimento da formação de conceitos, os dois processos se influenciam. A conciência reflexiva chega à criança 
através dos conhecimentos científicos e depois se transfere aos conceitos espontâneos (VYGOTSKY, 2001).

Fazendo referência ao tema deste artigo, pode-se entender que a Psicologia de Vygotsky entende a aprendizagem científica de modo diverso às explicações de Piaget.

\begin{abstract}
Poder-se-ia dizer que o desenvolvimento dos conceitos espontâneos da criança é ascendente, enquanto, o desenvolvimento dos seus conceitos científicos é descendente, para um nível mais elementar e concreto. Isso decorre das diferentes formas pelas quais os dois tipos de conceitos surgem (VYGOSTKY, 2001, p. 93).
\end{abstract}

A Área de Ensino de Ciências começou a se aproximar do discurso vigotskiano acerca da formação de conceitos pela insatisfação com as abordagens que evidenciam a aprendizagem por treinamento mecânico ou pelo espontaneísmo que privilegia unicamente as estruturas e operações psiclógicas inerentes ao sujeito. Assim, os conceitos de sujeito, de desenvolvimento, de aprendizagem expressos na obra de Vygotsky favorecem a crítica aos modelos tradicionais.

Esta ruptura com os modelos anteriores da pesquisa e da prática na área de Ensino de Ciências permite engendrar um novo lugar para o ensino de ciências na escola, pois possibilita pensar a educação científica, não apenas a partir dos estudos sobre novas metodologias, mas, também, a partir da perspectiva de como acontece a formação de conceitos e de como esse processo pode acontecer não apenas no momento da etapa do desenvolvimento lógico formal.

E é exatemente esta abordagem que favorece pensar o ensino de ciências nos anos iniciais da vida escolar, pois não é preciso esperar o desenvolvimento final do pensamento lógico formal para se ensinar os conceitos científicos. Pois o domínio de um nível mais elevado no campo dos conceitos científicos, eleva o nível dos conceitos espontâneos. E os conceitos espontâneos possibilitam o conceito científico. Há, de fato, uma interdependência.

Esta possibilidade de um novo tipo de relação entre Educação Científica e a Psicologia do Desenvolvimento ainda é recente e carece de pesquisas. Além disso, há muita resistência ao desenvolvimento da aprendizagem científica nos primeiros anos escolares, pois esse momento é identificado como tendo apenas um objetivo - o aprendizado da leitura e da escrita da língua portuguesa, já que a aprendizagem científica seria possível somente anos mais tarde. Entretanto, a partir das ideias de 
Vygotsky podemos pensar o vínculo entre leitura, escrita e aprendizagem científica de forma diferente.

[...] a articulação do ensino de Ciências com o processo [...] do aprendizado da leitura e da escrita da língua materna portuguesa, ainda apresenta para muitos docentes um problema [...]. As Ciências, naquilo que tem de mais relevante como a possibilidade de exploração e compreensão do meio social e natural [...] poderão contribuir para a inserção da criança à cultura científica (BRANDI e GURGEL, 2002, p. 113).

Mais do que isso, o conhecimento do mundo em que vivemos possibilita que a leitura e a escrita sejam desenvolvidas de forma contextualizada.

\begin{abstract}
a língua é um sistema de signos histórico e social que possibilita ao homems ignificar o mundo e a realidade. Assim, aprendê-la é aprender não só as palavras, mas também os seus significados culturais e, com eles, os modos pelos quais as pessoas do seu meio social entendem e interpretam a realidade e a si mesmas (PCN, 1997, p. 22).
\end{abstract}

Entretanto, a teoria de Vygotsky (1988) também permite o entendimento de como o desenvolvimento da leitura e da escrita não exclui a aprendizagem científica e nem precisa ser independente dela, o que justifica ainda mais aprendizagem científica nos anos inciais do ensino formal. Segundo o autor, o aprendizado da língua escrita fornece novo instrumento de pensamento, aumenta a capacidade de memória, produz novas formas de organizar a ação e de acesso à cultura. A escrita favorece passar da concretude da realidade para a abstração, elaborando nova forma de pensamento. Sendo assim, a aprendizagem científica e a aprendizagem da leitura e da escrita não são excludentes, mas podem beneficiar uma a outra.

Sendo assim, é importante a realização de pesquisas que analisem o ensino de ciências nas séries iniciais, pois até o início dos anos 2000 (LORENZETTI e DELIZOICOV, 2001), a pesquisa em ensino de ciências para as séries iniciais estava embasada por dois grandes objetivos: a formação de professores em ciências e as metodologias para o ensino de ciências. É importante o desenvolvimento de pesquisas na área de Ensino de Ciências que discutam a formação de conceitos científicos e seus vínculos com o conhecimento espontâneo para além dos modelos tradicionais. Para analisar a formação de conceitos, a Psicologia do Desenvolvimento pode ser um aporte teórico significativo para a área de Ensino de Ciências, desde que constituída para além do que alguns autores costumam nomear de psicologização da educação (FREITAS, 
1995), que restringe as questões da Educação apenas à dimensão do sujeito psicológico, existente nele mesmo, dissassociado das questões históricas, sociais e culturais.

\section{CONSIDERAÇÕES FINAIS}

Pode-se concluir inicialmente que a aprendizagem científica nos anos inciais da vida escolar pode ser significativa desde que seja desenvolvida para além dos modelos tradicionais da área de Ensino de Ciências que valorizavam o empirismo ou o subjetivismo. É preciso pensar novas formas de constituição de conceitos, tais como: desenvolvimento e aprendizagem, a fim de que seja possível afirmar a educação científica em momentos da vida que não seja apenas o do pensamento lógico formal constituído a partir da adolescência.

\section{REFERÊNCIAS}

ARRUDA, Sérgio e VILLANI, Alberto. "Mudança Conceitual no Ensino de Ciências". Cadernos Catarinenses de Ensino de Física, v. 11, n. 2, ago./1994, pp. 88-99.

BRANDI, A. T. E.; GURGEL, C. M. do A. Alfabetização científica e o processo de ler e escrever em séries iniciais: emergências de um estudo de investigação-ação. Ciência e Educação, São Paulo, v. 8, n.1, p.113-125, 2002.

BRASIL. Secretaria da Educação Fundamental. Parâmetros curriculares nacionais: Língua Portuguesa. Vol. 1. Brasília: MEC/SEF, 1997.

BRASIL. Secretaria da Educação Fundamental. Parâmetros curriculares nacionais: ciências naturais. Vol. 4. Brasília: MEC/SEF, 1997.

CACHAPUZ, A., PRAIA, J. e JORGE M. Da educação em ciência às orientações para o ensino das ciências: um repensar epistemológico . Ciência e Educação, São Paulo, v.10, n.3, 2004.

DELIZOICOV, D. ; ANGOTTI, J. A. e PERNAMBUCO, M. M. Ensino de ciências: fundamentos e métodos. São Paulo: CORTEZ, 2002.

DELIZOICOV, D. e LORENZETTI, L. Alfabetização Científica no contexto das séries iniciais. Ensaio. V.3. n.1, jun. 2001. Disponível em: http://<www.portal.fae.ufmg.br/seer/index.php/ensaio/article/viewFile/35/66> Acesso em 30 de agoto de 2013, 13h15min.

DELIZOICOV, D. e ANGOTTI, J. A. Metodologia do ensino de ciências. São Paulo: Cortez, 1990.

FREITAS, M.T.A. Vygotsky e Bakhtin: Psicologia e Educação - um intertexto. $2^{\text {a }}$ edição. São Paulo: Editora Ática, 1995.

KRASILCHIK, M. Reformas e realidade: o caso do ensino das ciências. São Paulo em Perspectiva, São Paulo, v.14, n.1, 2000, p. 85-93

REGO, T.C. Vygotsky: uma perspectiva histórico-cultural da Educação. $10^{\mathrm{a}}$ edição. Petrópolis: Vozes, 2000.

VYGOTSKY, L. Pensamento e Linguagem. $10^{\text {a }}$ edição. Petrópolis: Vozes, 2001. 
Ensino, Saúde e Ambiente - V6 (3), pp. 218-227, dez. 2013

VYGOTSKY, L; LURIA, A. e LEONTIEV, A. Linguagem, Desenvolvimento e Aprendizagem. São Paulo, Ícone, 1988.

VYGOTSKY, L. A Formação Social da Mente. São Paulo: Martins Fontes, 1984. 